\title{
Rachana Vidhi: Metode Desain Interior Berbasis Budaya Lokal dan Revolusi Industri 4.0
}

\author{
I Kadek Dwi Noorwatha ${ }^{\mathrm{a}, 1, *}$, Putu Ari Darmastuti ${ }^{\mathrm{b}, 2}$, Ni Luh Kadek Resi Kerdiati ${ }^{\mathrm{c}, 3}$ \\ ${ }^{a}$ Senior Lecturer of Interior Design Department, Indonesia Institut of the Art, Denpasar Jl. Nusa Indah, Denpasar-Bali, 80235, Indonesia \\ ${ }^{\mathrm{b}}$ Lecturer of Interior Design Department, Indonesia Institut of the Art, Denpasar Jl. Nusa Indah, Denpasar-Bali, 80235, Indonesia \\ ${ }^{\mathrm{c}}$ Lecturer of Interior Design Department, Indonesia Institut of the Art, Denpasar Jl. Nusa Indah, Denpasar-Bali, 80235, Indonesia \\ 1 noorwatha@isi-dps.ac.id*; ${ }^{2}$ putuari@isi-dps.ac.id; ${ }^{3}$ resikerdiati@isi-dps.ac.ic \\ * Corresponding Author
}

Received 2020-07-08; accepted 2020-09-17; published 2020-12-19

\begin{abstract}
ABSTRAK
Penelitian ini merupakan penelitian fundamental yang berupaya merumuskan suatu metode desain interior berbasis budaya lokal dan revolusi industri 4.0 yang disebut Rachana Vidhi. Permasalahan penelitian muncul dari kebutuhan mendesak akan perumusan metode desain interior yang ideal, yang memadukan perkembangan budaya lokal, kebutuhan industri desain interior dan mengimplementasikan semangat revolusi industri 4.0. Metode penelitian menggunakan pendekatan studi dokumen kualitatif khusus dengan metode telaah sistematis yang dipadukan dengan metode komparatif. Hasil penelitian metode Rachana Vidhi telah dibahas dengan kerangka dasar tahapan organisasi profesi HDII sebagai sinergi antara akademisi dan organisasi profesi. Metode ini juga menyeimbangkan pengetahuan dan kemampuan antara akademisi dan praktisi dengan paradigma 'desain berbasis penelitian'. Dalam konteks pengembangan budaya, metode desain interior Rachana Vidhi telah diisi pada tahap Predesain terutama pada tahap no. 15 Eksplorasi Budaya, sebagai bagian dari penyusunan konsep desain interior. Sinergi dengan revolusi industri 4.0 pada metode desain interior Rachana Vidhi diterapkan pada tahapan Input, Design, Conceptual Design dan Design Development. Aplikasi revolusi industri 4.0 yang digunakan adalah untuk pencarian wawasan, pengumpulan data dan pemodelan.
\end{abstract}

\section{Rachana Vidhi: Interior Design Methods Based on Local Culture and the Industrial Revolution 4.0}

\section{ABSTRACT}

This research is a fundamental research that seeks to formulate an interior design method based on local culture and the industrial revolution 4.0 called 'Rachana Vidhi'. The research problem arises from the urgent need for the formulation of an ideal interior design method, which combines the development of local culture, the needs of the interior design industry and implements the spirit of the industrial revolution 4.0. The research method uses a qualitative document study approach specifically with the systematic review method, which is combined with the comparative method. The reseach results of the 'Rachana Vidhi' method have been discussed using the basic framework of the stages of the HDII professional organization as a synergy between academics and professional organizations. The method also balances knowledge and abilities between academics and practitioners with the 'research based design' paradigm. In the context of cultural development, the interior design method 'Rachana Vidhi' has been filled in at the 'Predesain' stage especially at step no. 15 Cultural Exploration, as part of the drafting of interior design concepts. Synergy with the industrial revolution 4.0 on the interior design method 'Rachana Vidhi' is applied to the stages of Input, Design, Conceptual Design and Design Development. Industrial revolution 4.0 application used is for insight searching, data collecting and modeling.

\section{KEYWORDS}

Interior Design

Method

Industrial Revolution

4.0

Culture Based Design

This is an open access article under the CC-BY-SA

license

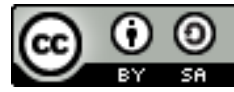




\section{Pendahuluan}

Pendidikan desain interior di Indonesia dalam menghadapi era revolusi industri 4.0 dan society 5.0 berhadapan dengan fenomena perubahan yang ekstrem (disrupsi) pada segala aspek kehidupan manusia yang berhubungan dengan interaksi dengan internet. Oleh karena itu pendidikan desain interior wajib menyempurnakan kurikulumnya sebagai persiapan membentuk anak didik yang sigap menghadapi dua peristiwa di atas. Menurut Muhadjir Effendy, bahwa merambahnya revousi industri 4.0 masuk ke dalam dunia pendidikan maka diperlukan perbaikan kurikulum dengan peningkatan kompetensi peserta didik, antara lain (1) Critical thinking (2) Creativity and innovation (3) Interpersonal skill and communication (4) Teamwork and collaboration dan (5) Confident (Yusnaini and Slamet 2019). World Economic Forum (WEF) pada 2018 bahkan menyebutkan, setidaknya ada 10 kemampuan harus dikuasai manusia pada 5 tahun mendatang. Beberapa di antaranya adalah pemikiran analitis, kreativitas, orisinalitas, inisiatif yang tinggi, pemecahan masalah yang kompleks, dan kecerdasan emosional . Paradigma pendidikan desain interior kekinian, wajib mengaplikasikan peningkatan kompetensi tersebut, khususnya pada mata kuliah utama yang diajarkan dalam studio desain. Maka dari itu, dalam pengembangan konten pembelajaran pada mata kuliah utama memerlukan suatu rumusan metode dalam menghasilkan karya desain interior yang berkualitas yang sejalan dengan kebutuhan industri.

Hal tersebut sejalan dengan Standard 2 dari CIDA (Council of Interior Design Accreditation) yaitu menekankan pengetahuan desain interior kekinian dengan paradigma Global Perspective for Design (khususnya pada indikator $2 \mathrm{~g}$ ). Standar 2 menspesifikasikan bahwa program pendidikan desain interior wajib memberikan kesempatan untuk mengembangkan pengetahuan desain interior dari budaya lokal di dunia (di luar Amerika dan Eropa sebagai barometer perkembangan industri dan Pendidikan desain interior internasional) (CIDA 2010). Penulis mengajukan metode desain interior berbasis budaya lokal dan revolusi industri 4.0 yang dinamakan Rachana Vidhi. Istilah tersebut merupakan gabungan dua kata dalam bahasa Sansekerta yaitu 'रचना' (Rachana) berarti desain dan विधि' (vidhi) berarti metode atau formula. Maka Rachana vidhi dapat diartikan sebagai metode desain. Penggunaan bahasa Sansekerta sebagai implementasi kearifan lokal Bali yang dekat dengan bahasa Sansekerta sebagai lingua franca dalam budaya bercorak Hinduisme.

Permasalahan yang timbul dalam pemaparan di atas adalah kebutuhan yang mendesak tentang rumusan metode desain interior yang ideal. Ideal yang dimaksud adalah relevan dalam pengembangan budaya lokal sebagai basis wawasan untuk penguatan identitas desain modern. Sekaligus metode tersebut mengimplementasikan spirit revolusi industri 4.0, sebagai sebuah fenomena kekinian dalam segala aspek kehidupan manusia modern di era digital. Tujuan khusus dalam penelitian ini adalah menemukan rumusan metode desain interior yang berbasis budaya lokal yang relevan dengan revolusi industri 4.0. Metode temuan ini akan dijadikan basis konten pembelajaran mata kuliah utama pada studio desain di Program Studi Desain interior ISI Denpasar.

\section{Metode}

Metode penelitian menggunakan pendekatan kualitatif dalam dua tahapan penelitian. Tahap pertama adalah mengumpulkan beragam artikel dan tulisan sebelumnya yang berhubungan dengan topik penelitian dengan metode systematic review. Systematic review adalah suatu metode penelitian untuk melakukan identifikasi, evaluasi dan interpretasi terhadap semua hasil penelitian yang relevan terkait pertanyaan penelitian tertentu, topik tertentu, atau fenomena yang menjadi perhatian (Kitchenham 2004). Tahap kedua adalah dengan metode komparatif yaitu penelitian yang membandingkan keadaan satu variabel atau lebih pada dua atau lebih sampel yang berbeda, atau dua waktu yang berbeda (Sugiyono 2008). Hasil dari komparasi tersebut akan disintesis menjadi simpulan penelitian, berupa skema metode desain interior berbasis budaya lokal dan revolusi industri 4.0. 


\section{Hasil dan Pembahasan}

\subsection{Studi Metode Desain Interior}

John Christopher Jones dalam bukunya 'Design Methods Seed of Human Futures' (1970) menegaskan bahwa metodologi (desain) seharusnya bukan sebuah jalur 'tetap' untuk sebuah tujuan yang pasti, namun sebuah perbincangan tentang semuanya dapat diwujudkan (Jones 1992). Pernyataan Jones tersebut menegaskan bahwa metode desain tersebut pada hakekatnya bersifat kontekstual dan dapat dikondisikan sesuai dengan kebutuhan proses desain. Peter Lloyd dengan artikel yang berjudul 'You Make It and You Try It Out: Seeds of Design Discipline Futures' (2019) menyatakan bahwa setiap desainer mempunyai hak untuk membuat metode desainnya sendiri (Lloyd 2019). Metode desain meskipun tampaknya bertujuan untuk mencapai tujuan praktis, bukanlah instrumen politis yang bersifat netral. Metode desain mewujudkan, dan mungkin menyamarkan atau memprioritaskan jenis pengetahuan tertentu. Pengembangan metode desain baru semakin dipandang sebagai kendaraan yang efektif untuk mengartikulasikan jenis pengetahuan tertentu, meningkatkan kesadaran dengan cara pengalaman dan kolaboratif tentang isu-isu tertentu yang penting bagi perancang metode desain (Lloyd 2019, 176).

Kilmer dan Kilmer (Kilmer and Kilmer 2014, 177) menjelaskan bahwa proses mendesain interior melibatkan proses pendefinisian masalah, menghasilkan dan mengevaluasi alternatif pemecahan masalah, serta setelah mendapatkan pemecahan solusi masalah yang terpilih diakhiri dengan menerapkan solusi tersebut ke dalam lingkungan interior. Desain dapat dilihat sebagai strategi penyelesaian masalah dimana kemampuan kreatif memanfaatkan seni, ilmu pengetahuan dan teknologi untuk menghasilkan solusi untuk permasalahan lapangan. Desain interior yang baik bukan hanya terjadi secara kebetulan namun itu adalah sebuah proses yang sistematis dan direncanakan untuk menghasilkan interior yang secara visual tampil estetis, menyenangkan, nyaman dan fungsional, untuk meningkatkan kualitas hidup civitas baik fisikis maupun psikis. Santosa (Santosa 2006, 115) memaparkan metode analitis (analitical method) sebagai dasar proses desain. Hal ini mengacu pada metodologi desain (Jones 1970) sebagai formulasi dari apa yang dinamakan 'berpikir sebelum menggambar' (thinking before drawing). Metode analisis menjadikan proses mendesain pada hakekatnya adalah sebuah proses meneliti, yang hasil akhirnya adalah karya desain itu sendiri.

Penulis merangkum beberapa metode desain interior dari tahun 2003-2017 baik dari penulis asing, lokal dan organisasi profesi menunjukkan pola yang sama. Beragam metode tersebut menunjukkan beberapa perbedaan meskipun mengacu ke pola dasar yang sama yaitu (1) Masukan (Input) (2) Proses dan (3) Luaran (Output) dan (4) Evaluasi. Beragam metode tersebut masih digabung tahapannya antara tahapan praktisi dan juga akademisi. Pada beberapa metode tersebut juga menunjukkan bagaimana proses desain interior tersebut juga merupakan kegiatan ilmiah dengan menekankan (1) perumusan masalah (2) hipotesis (3) studi literatur (4) metode (5) analisis (6) sintesis (7) simpulan; yang dapat dikomparasikan seperti tampak pada Figure 1 berikut. 


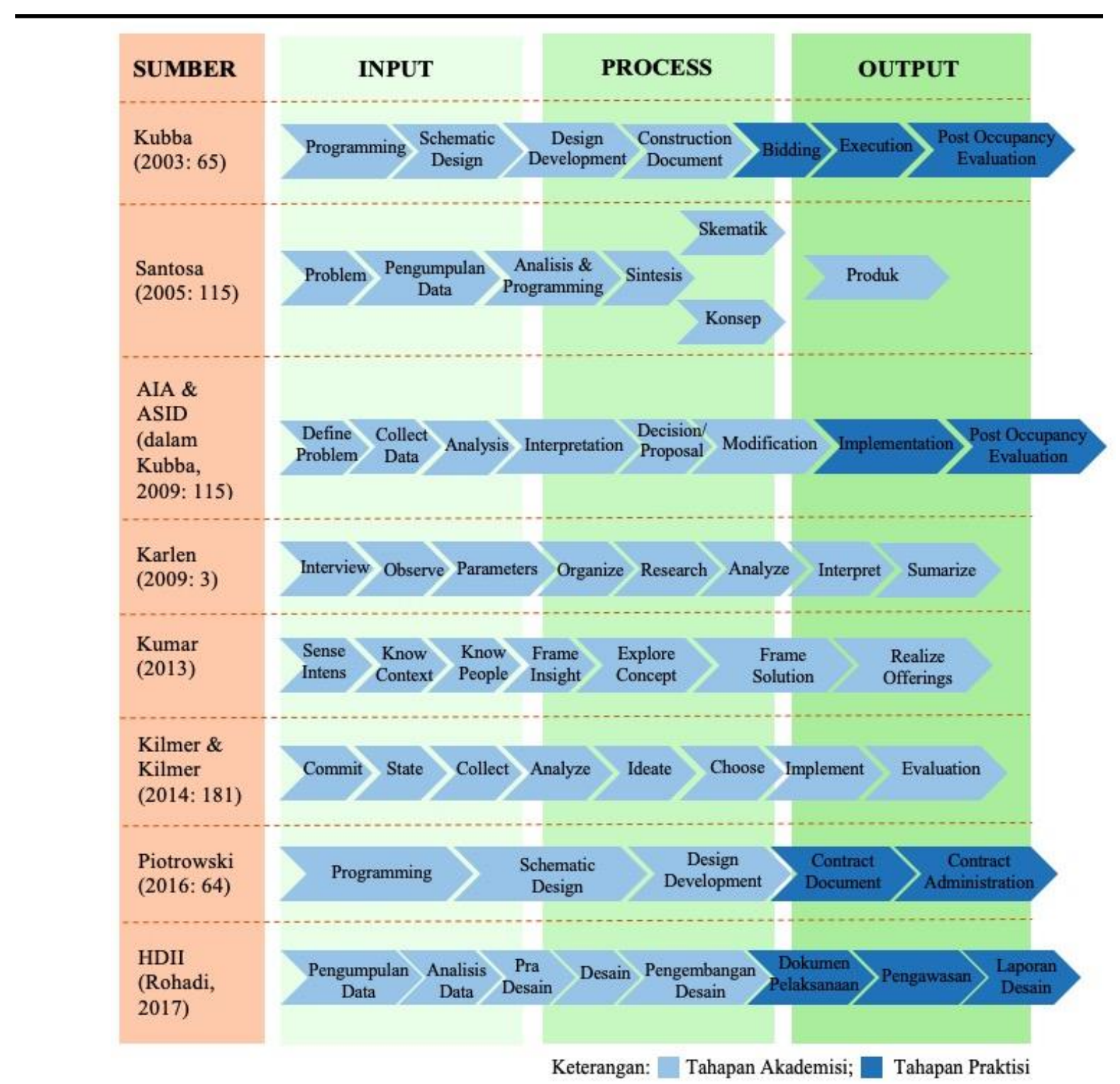

Fig. 1. Komparasi Metode Desain Interior (2003-2017) (Kilmer and Kilmer 2014), (Karlen and Fleming 2016), (Kubba 2003), (Kumar 2012), (Piotrowski and Rogers 2010), (Santosa 2006), (Kubba 2009),

(Rohadi 2017)

Dalam proses studio desain boleh dikatakan hasil karya desain merupakan suatu hasil hipotesis yang berupa gambar 'produk' desain interior. Produk seorang desainer interior dapat disesuaikan dengan tahapan pengerjaan dalam proses mendesain interior, yaitu: (1) Dokumen Pemograman Ruang (2) Desain Konseptual (3) Dokumen Pengembangan Desain (4) Dokumen Konstruksional (5) Dokumen Administrasional (RAB, RKS dan Dokumen Tender) (Grimley and Love 2018, 20). Dalam konteks desain, hasil produk desain interior tersebut wajib menunjukan suatu solusi kreatif-inovatif dalam menyelesaikan masalah objek kasus. Dalam konteks seni visual, hasil produk desain wajib menunjukan suatu kualitas estetik pada representasi desainnya, juga kebenaran kode gambar disesuaikan dengan standard gambar teknik.

Pada proses representasi desain tersebut mahasiswa dalam studio desain ditekankan penggunaan teknik penggambaran manual drawing khususnya desain konseptual, meskipun untuk mencapai kualitas estetis tertentu menggunakan bantuan digital untuk retouching dan komposisi. Desain konseptual yaitu gambar yang akan dipresentasikan ke klien, jadi dibuat seindah mungkin untuk meyakinkan klien terhadap hasil desain yang telah dibuat. Selanjutnya dokumen pengembangan desain adalah gambar pengembangan dari desain konseptual yang telah menyerap masukan, aspirasi klien ketika presentasi desain konseptual. Dokumen Desain Pengembangan adalah gambar kerja yang 
bersifat teknikal yang akan digunakan pada proses tender, atau bisa diberikan ke kontraktor untuk membangun desain tersebut.

Kadangkala metode desain yang terlalu kaku justru mengekang inspirasi dan intuisi kreatif desainer untuk menghasilkan karya desain interior yang menciptakan 'Aha Moment' dengan 'Wow Factor' yang tinggi pada pengamat. Kesesuaian dengan metode ilmiah justru membuat desainer menjadi 'sangat scientific' dan mengabaikan unsur 'fun' dalam mendesain. Meskipun John Christoper Jones (Jones 1970) sendiri mengemukakan metode bukanlah suatu 'aturan kaku' yang menutup peluang pengembangan. Keseimbangan antara sisi artistik dengan scientific dalam mendesain memerlukan suatu metode yang lebih fleksibel ketika diterapkan ke dalam studio desain, pada mahasiswa dengan beragam tingkat kemampuannya. Begitu juga arahan Dirjen Belmawa Ristekdikti (2018) yang membedakan tingkat kedalaman dan keluasan materi pembelajaran antara Diploma III dan Diploma IV/Sarjana Strata 1 (S1). Diploma III ditekankan untuk menguasai konsep teoritis bidang pengetahuan dan keterampilan tertentu secara umum; dengan Diploma IV dan Sarjana (S1) yang menguasai konsep teoritis bidang pengetahuan dan keterampilan tertentu, secara umum dan konsep teoritis bagian khusus dalam bidang pengetahuan dan keterampilan tersebut secara mendalam (Belmawa 2018, 12).

Pada tingkat kedalaman dan keluasan materi pembelajaran untuk tingkat Strata 1 untuk non vokasional, adalah penekanan pada kegiatan riset dan proses pembelajaran. Untuk memformulasi sebuah metode baru yang berbasis budaya lokal dan revolusi industri 4.0 yang dinamakan 'Rachana Vidhi', memerlukan beragam pertimbangan. Kerangka dasar metode desain interior akan menggunakan arahan dari Himpunan Desainer Interior Indonesia-HDII (Rohadi 2017). Pada pembahasan selanjutnya akan menggabungkan antara metode pengembangan budaya lokal dalam desain interior dan sinergi dengan revolusi industri 4.0.

\subsection{Metode Pengembangan Budaya Lokal dalam Desain Interior}

Pembahasan sumber daya budaya sebagai tulang punggung industri kreatif sejalan dengan istilah 'Ekonomi Jingga' (The Orange Economy) yang mengembangkan gagasan mengenai pengembangan budaya ke dalam industri kreatif. Restrepo dan Marquez (2013) menjelaskan bahwa 'Ekonomi Jingga' (The Orange Economy) adalah kelompok kegiatan terkait yang melaluinya gagasan diubah menjadi barang dan jasa budaya yang nilainya ditentukan oleh kekayaan intelektual. Ruang lingkup 'jingga' sebagai simbol kebahagiaan (happy), meliputi: 1) Ekonomi Budaya dan industri kreatif yang berbagi Industri Budaya Konvensional; dan 2) kegiatan pendukung kreativitas (Buitrago Restrepo and Duque Márquez 2013). Lebih jauh Restrepo dan Marquez membagi ekonomi jingga ke dalam ekonomi kultural dan industri kreatif. Ekonomi budaya terdiri dari semua kegiatan artistik tradisional, semua kegiatan yang terkait dengan pelestarian dan transmisi warisan budaya, dan industri budaya konvensional.

Industri kreatif menggabungkan industri budaya konvensional dan penciptaan fungsional, media baru dan perangkat lunak. Muara dari dua entitas ekonomi jingga adalah kegiatan pendukung kreativitas yang dapat dibagi lagi menjadi (1) Riset kreatif (Research), Pengembangan (Development), dan inovasi (Inovation): R + D + I (2) Pengembangan keterampilan teknis untuk kegiatan kreatif (3) Pengaturan dan Hak Kekayaan Intelektual (4) Pendidikan kreatif profesional (Buitrago Restrepo and Duque Márquez 2013, 40). Pengembangan budaya dalam konteks industri kreatif dinamakan desain kultural (cultural design), yang menurut Rubin berarti desain yang relevan secara budaya. Hal tersebut mengacu pada pertimbangan dan implementasi elemen budaya target pasar ke dalam desain produk dengan nilai estetika, fungsional dan emosional yang lebih besar (Rubin 2012). Liang membagi jenis level kebudayaan yang dapat dikembangkan ke dalam desain interior sebagai bagian dari industri kreatif (Liang 2014).

Pertama adalah budaya level luar (outer culture) mengacu pada objek dan beberapa hal konkret. Dalam desain interior dan arsitektur budaya level luar terutama mengacu pada bentuk dan artefak budaya, seperti kurva atap arsitektur tradisional, kerangka kayu, sambungan kayu (joinery), koridor, jendela dan pintu, pola dekoratif, dll. Budaya level tengah (intermediate culture) sebagai kombinasi antara pikiran dan materi, budaya level tengah mengacu pada metode, formula, dan aturan konkret, seperti pelengkap bentuk geometri \& natural, interaksi spasial, mode perilaku manusia \& desain ruang, dan teknik organisasi ruang. Budaya level dalam (deep culture) adalah adalah budaya spiritual, termasuk pemikiran keagamaan, karakter nasional, dll (Liang 2014). 
Table 1. Kedalaman Budaya pada Pengembangan Desain (Rubin 2012)

\begin{tabular}{|c|c|c|c|}
\hline Level Kedalaman & Budaya & Desain Kultural & $\begin{array}{c}\text { Desain Emosional (Donald } \\
\text { Norman) }\end{array}$ \\
\hline $\begin{array}{c}\text { Ekstrinsik/ } \\
\text { Eksplisit/Kulit }\end{array}$ & $\begin{array}{c}\text { Budaya } \\
\text { Material dan } \\
\text { Visual } \\
\end{array}$ & $\begin{array}{l}\text { Level terluar (Outer) (Warna, } \\
\text { tekstur, bentuk dan Pola) }\end{array}$ & $\begin{array}{c}\text { Desain Visual (Estetik, } \\
\text { Bentuk dan Penggayaan } \\
\text { (styling) }\end{array}$ \\
\hline $\begin{array}{l}\text { Median/Isi } \\
\text { (Pragmatis) }\end{array}$ & $\begin{array}{c}\text { Budaya } \\
\text { Perilaku } \\
\text { Sosial }\end{array}$ & $\begin{array}{l}\text { Level Tengah (Fungsi, Operasi, } \\
\text { Penggunaan, Keamanan) }\end{array}$ & $\begin{array}{l}\text { Desain Perilaku (keteknikan, } \\
\text { fungsi, dan penggunaan } \\
\text { (usability) }\end{array}$ \\
\hline $\begin{array}{l}\text { Intrinsik/Implisit/ } \\
\text { Esensi (Filosofis) }\end{array}$ & $\begin{array}{l}\text { Budaya } \\
\text { Spiritualitas } \\
\text { Ideal }\end{array}$ & $\begin{array}{l}\text { Level Terdalam (Inner) (Cerita, } \\
\text { emosi dan fitur budaya) }\end{array}$ & $\begin{array}{l}\text { Desain Reflektif (perhatian, } \\
\text { emosi dan hasrat) }\end{array}$ \\
\hline
\end{tabular}

\subsection{Sinergi dengan Revolusi Industri 4.0}

Korelasi antara keilmuan desain dan teknologi tidak dapat dipisahkan, menurut sejarahnya desain memang lahir dari revolusi industri yang berhubungan dengan aplikasi teknologi. Atas kedekatan tersebut, maka dalam wacana revolusi industri 4.0 sekarang ini, hubungan desain interior selain menggunakan teknologi digital dalam proses penuangan gagasan juga menggunakan teknologi dalam pengolahan data melalui akses digital, cloud computing, interaktif dan networking secara real time. Desainer juga wajib memahami bagaimana kehidupan digital berbasis internet yang mempengaruhi persepsi dan perilaku manusia dalam ruang dan seluruh elemen pembentuk interiornya. Tujuan akhirnya adalah kecepatan berproses, lintas batas, inovasi produk interior dan perikehidupan manusia di era digital (digital living). Penerapan teknologi pada industri desain interior pada intinya adalah mengakomodir aspek kecepatan produksi, presisi dan keluasan insight desain.

Table 2. Hubungan Antara Disiplin Ilmu dan Praktik Desain, Tujuan, dan Teknologi pada Revolusi Industri 4.0 (Celaschi 2017)

\begin{tabular}{|c|c|c|}
\hline Tujuan & Teknologi & Konsekuensi Desain \\
\hline $\begin{array}{l}\text { Kecepatan } \\
\text { Pengurangan biaya } \\
\text { produksi } \\
\text { Kustomisasi massal }\end{array}$ & $\begin{array}{c}\text { Cad 2D.3D rendering digital } \\
\text { modelling } \\
\text { CAE (fem etc.) } \\
\text { Additive production }\end{array}$ & $\begin{array}{l}\text { Digital memecah pembagian antara produksi } \\
\text { dan desain, dan desain tidak dapat dilakukan } \\
\text { setelah definisi struktur produk. }\end{array}$ \\
\hline $\begin{array}{l}\text { Kepastian hasil } \\
\text { Kualitas } \\
\text { Kustomisasi } \\
\text { Interkoneksi dengan } \\
\text { jaringan penyedia }\end{array}$ & $\begin{array}{c}\text { Cloud } \\
\text { Digital modelling of the } \\
\text { production system }(\mathrm{cps}) \\
\text { Digital networks } \\
\text { IIOT }\end{array}$ & $\begin{array}{l}\text { Desain sistem menjadi protagonis yang } \\
\text { memungkinkan berbagai aktor di berbagai } \\
\text { tingkatan rantai untuk bertindak atau } \\
\text { mengendalikan kemajuan proses desain (co- } \\
\text { desain dan desain } 2.0 \text { ). }\end{array}$ \\
\hline $\begin{array}{l}\text { Pemeliharaan terprediksi } \\
\text { Pemeliharaan produk } \\
\text { (transisi dari produk ke } \\
\text { pelayanan) }\end{array}$ & $\begin{array}{c}\text { IIOT } \\
\text { Sensors } \\
\text { Big data \& analytics } \\
\text { Augmented reality } \\
\end{array}$ & $\begin{array}{c}\text { Koneksi digital antara pabrikan dan } \\
\text { pelanggan yang menyediakan layanan. } \\
\text { Desain layanan menjadi pusat penciptaan } \\
\text { nilai. }\end{array}$ \\
\hline $\begin{array}{l}\text { Inovasi disruptif dan } \\
\text { generasi sistem produk } \\
\text { kolektif (kota pintar) } \\
\text { Antisipasi }\end{array}$ & $\begin{array}{c}\text { IOB } \\
\text { SENSORS } \\
\text { GPS } \\
\text { Big data \& analytics } \\
\text { Digital modelling } \\
\text { Additive manufacturing }\end{array}$ & $\begin{array}{l}\text { Rintangan antara B2B dan B2C jatuh, desain } \\
\text { adalah praktik dan pengetahuan yang dapat } \\
\text { memediasi antara dua dunia yang saat ini } \\
\text { berbicara bahasa dan menilai informasi yang } \\
\text { sangat berbeda satu sama lain. }\end{array}$ \\
\hline
\end{tabular}

Pada studio desain dalam menunjang perkuliahan mata kuliah utama, aplikasi revolusi industri akan dilakukan secara blended learning yang ditekankan pada:

1) Proses Mendesain yaitu dengan revolusi industri 4.0, desainer dapat mendisrupsi proses mendesain dengan memanfaatkan teknologi internet dalam hal:

- Insight Searching yaitu mencari parameter desain, image inspirasi (pinterest, instagram, dll) dan konten desain secara opensource (3D Warehouse), yang digunakan sebagai peluasan wawasan dan pengetahuan desain mahasiswa. 
- Data collecting yaitu mengumpulkan data yang sesuai kebutuhan proses desain seperti review pengunjung objek kasus khusus interior non residensial (menggunakan review dan comment pada aplikasi wisata atau google map), data sun path, wind analysis, data produk dan materialitas terbaru, data dari objek kasus (kuisioner pengguna melalui google form dll). Pada data collecting juga, desainer dapat menggunakan fakta penelitian yang mendukung dalam proses desain melalui Evidence-Based Design (EBD).

- Desain partisipasi/kolaborasi yaitu dengan mengajak pengguna ruang untuk ikut bersama-sama menuangkan harapan, idealitas dan keinginannya secara real time. Desain pun dibuat seinteraktif mungkin dengan media virtual reality sehingga pengguna ruang langsung dapat merasakan proses peubahan ruang tersebut.

- Modelling yaitu menggunakan teknologi pengolah grafis baik $2 D$ maupun $3 D$ untuk menghasilkan kualitas karya desain yang sesuai standar profesional. Mahasiswa juga dapat mengekplorasi bentukan parametrik hasil pengolahan software yang lebih memberikan bentuk desain yang nirbatas dibandingkan bentukan tradisional (conventional drawing), dengan tetap mempertahankan intuisi estetiknya. Desainer juga dapat mengaplikasikan langsung desainnya dengan modelling sekaligus prototyping dengan teknologi $3 D$ Printer.

- Presentasi dengan menggunakan teknologi presentasi yang sekaligus interaktif dengan pengamatnya. Mahasiswa dapat menggunakan teknologi multimedia ataupun virtual (virtual reality dan augmented reality) dalam mempresentasikan karya desainnya, agar dapat meyakinkan kliennya.

- Originalitas dengan menggunakan teknologi dapat mencegah tindakan plagiarisme dan pelanggaran hak cipta ketika proses desain, sekaligus mendidik mahasiswa agar sadar memanfaatkan hak kekayaan intelektualitasnya dalam mendesain.

2) Aplikasinya pada Objek Interior yaitu dengan pengetahuan revolusi industri 4.0, mahasiswa dapat mengeksplorasi teknologi desain pada objek desainnya, dengan aplikasi:

- Sistem yaitu mahasiswa dapat mendesain sistem dalam desain interior objeknya disesuaikan dengan aplikasi revolusi industri 4.0. Contohnya bagaimana mendesain interior non residensial yang terintegrasi dengan aplikasi di mobile phone, baik untuk registrasi, pricing dan stocking yang mempengaruhi layout dari interior itu sendiri. Mahasiswa juga dapat berinovasi untuk menciptakan start up yang mengintegrasikan antara aplikasi dengan fisikal interior terbangun, untuk mendisrupsi pola aktivitas dan gaya hidup pengguna ruang

- Smart Material yaitu mahasiswa dapat menggunakan material pintar yang dapat diprogram untuk mengakomodir kebutuhan dalam ruang. Misalnya perubahan material pelapis dinding yang lebih terkontrol dengan sistem sensor, sehingga visualnya dapat mengubah mood pengguna ruang.

- Internet of Thing (IoT) yaitu mahasiswa dapat mendesain interior yang terintegrasi dengan IoT berupa controling, surveilance dan juga otomatisasi, yang sesuai dengan kebutuhan society 5.0 dengan aplikasi revolusi industri 4.0.

Seluruh metode tersebut baik metode desain interior, metode pengembangan budaya dan sinergi dengan revolusi industri 4.0; akan diformulasikan menjadi sebuah metode desain interior yang dipraktikan secara blended learning dalam studio desain interior, dinamakan Rachana Vidhi.

\section{Pengembangan Rachana Vidhi}

Dari pemaparan sebelumnya maka akan disusun sebuah metode desain interior yang dinamakan 'Rachana Vidhi'. Rachana Vidhi menggunakan lima tahapan yang disebut 'Pancaksana' (dari Bahasa Bali kuno, 'panca' berarti 'lima' dan 'ksana' yang berarti langkah). Pancaksana sebagai bagian dari metode 'Rachana Vidhi' terdiri dari:

- Tahapan Input: Pada tahapan ini mahasiswa dikenalkan pada teknik pengumpulan data berdasarkan tiga unsur pokok desain interior yaitu pembahasan korelasi antara lingkungan, manusia dan interior itu sendiri. Pada tahapan ini mahasiswa juga menentukan permasalahan interior objek kasusnya, merupakan kesenjangan ( $\mathrm{gap}$ ) antara fakta lapangan, idealitas manusia 
dan potensi pengembangan (space for change). Mahasiswa mengumpulkan data sebagai dasar proses desain selanjutnya yang terinci sebagai berikut: (1) Pemahaman Objek kasus, (2) Karakteristik Eksternal Interior, (3) Karakteristik Internal Interior, (4) Data Lapangan, (5) Idealitas Manusia, (6) Fakta Interior dan (7) Masalah Interior.

- Tahapan Proses: Pada tahapan ini mahasiswa mengolah data yang didapatnya untuk menghasilkan sintesa desain yang digunakan sebagai penyelesaian masalah yang ditemukan pada tahapan sebelumnya Tahapan ini terdiri dari: (8) Analisis (9) Sintesis.

- Tahapan Pradesain: Pada tahapan ini mahasiswa mengembangkan sintesis ke visual melalui proses eksplorasi kreatif-inovatif. Pada tahapan ini juga mahasiswa mulai mengeksplorasi budaya lokal sesuai Visi\& Misi Jurusan. Tahapan pradesain terdiri dari: (10) Tujuan (11) Konsep Umum (12) Kriteria, (13) Konsep Dasar, (14) Ide \& Gagasan (15) Eksplorasi Budaya, (16) Konsep Perwujudan.

- Tahapan Output (Desain Konseptual): Pada tahapan ini mahasiswa menyusun program ruang dan dokumen kerja desain untuk presentasi desain, sehingga dibuat se -artistik mungkin. Tahapan ini terdiri dari (17) Penyusunan Program Ruang (18) Skenario Aktivitas \& Analisis Kebutuhan Ruang (19) Besaran Ruang (20) Bagan Orgnisasi Ruang (21) Zonasi Ruang (22) Sirkulasi (23) Gubahan Ruang (24) Desain Layout (25) Desain Penataan Fasilitas (26) Potongan (27) Tampak Fasad (28) Perspektif (29) Prototyping/Simulasi.

- Tahapan Output (Pengembangan Desain): Pada tahapan ini mahasiswa mengembangkan desain konseptual berdasarkan masukan dari klien atau pengguna ruang objek kasus. Pada tahapan ini mahasiswa membuat gambar teknik interior sesuai standar. Tahapan ini terdiri dari: (30) Revisi dan Pengembangan (31) Desain Pengembangan (32) Detail Drawing (33) Draft Administrasi Proyek (Rancangan Anggaran Biaya (RAB) dan Rencana Kerja \& Syarat (RKS).

Skema metode desain interior Rachana Vidhi dapat terlihat pada Figure 2, metode tersebut menggunakan sistem linear, dalam artian mahasiswa mengikuti setiap langkah dalam satu tahapan satu persatu, dengan selalu mengadakan evaluasi ke tahapan sebelumnya sebagai umpan balik (feed back). Pada lima tahapan (pancaksana) tersebut, mahasiswa akan dididik pada studio desain interior untuk menyeimbangkan antara pengetahuan akademisi, proses kreatif \& inovatif, mengembangan budaya dan juga disesuaikan dengan persyaratan industri. Pada tataran akademisi mahasiswa ditekankan untuk melakukan riset pendukung khususnya pada pengumpulan data, analisis dan sintesis. Pada tataran kreatif dan inovatif khususnya pada tahapan pradesain, mahasiswa dibebaskan untuk mengeksplorasi ide dan membuat gagasan secara visual, beragam penyelesaian masalah desain interior pada objek kasus. Pada tataran tersebut juga, mahasiswa dikenalkan dengan budaya lokal sebagai inspirasi pengembangan desain, dengan tetap mempertahankan nilai budaya asalinya. Pada tataran pendidikan profesi, mahasiswa dikenalkan dengan syarat gambar kerja desain interior, sesuai standar organisasi profesi dan perundangan yang berlaku.

Metode pengembangan budaya dalam metode Rachana Vidhi mengedepankan pengenalan budaya sebagai dasar inspirasi pengembangan desain khususnya dalam pengembangan konsep. Indonesia kaya akan sumber daya budaya, sehingga mahasiswa tidak dibatasi dalam memilih budaya mana yang bisa dikembangkan ke dalam objek kasusnya. Pengembangan budaya tetap memperhatikan nilai budaya asalnya, sehingga tidak terkesan memutilasi budaya asli yang justru mendegradasi nilai intrinsik budaya tersebut. Mahasiswa diarahkan untuk eksplorasi budaya (nomor 15 pada tahapan Pra desain), dengan meninjau terlebih dahulu elemen budaya tersebut apakah berupa artifact (benda buatan manusia), mentifact (fakta mental berupa gagasan, ideologi dan cara berpikir) atau sosiofact (fakta sosial berupa ritual, nilai dan aktivitas sosial). Juga bagaimana mengembangkan budaya tersebut apakah pada tataran filosofis (terdalam), ritual \& aktivitas (menengah) ataupun artefak atau visual (permukaan). Pengembangan ideal dari sumber daya budaya tersebut membutuhkan kemampuan penerjemahan konten budaya ke dalam idiom estetik desain, yang relevan untuk mengakomodasi kehidupan modern, tanpa mencederai budaya aslinya. 

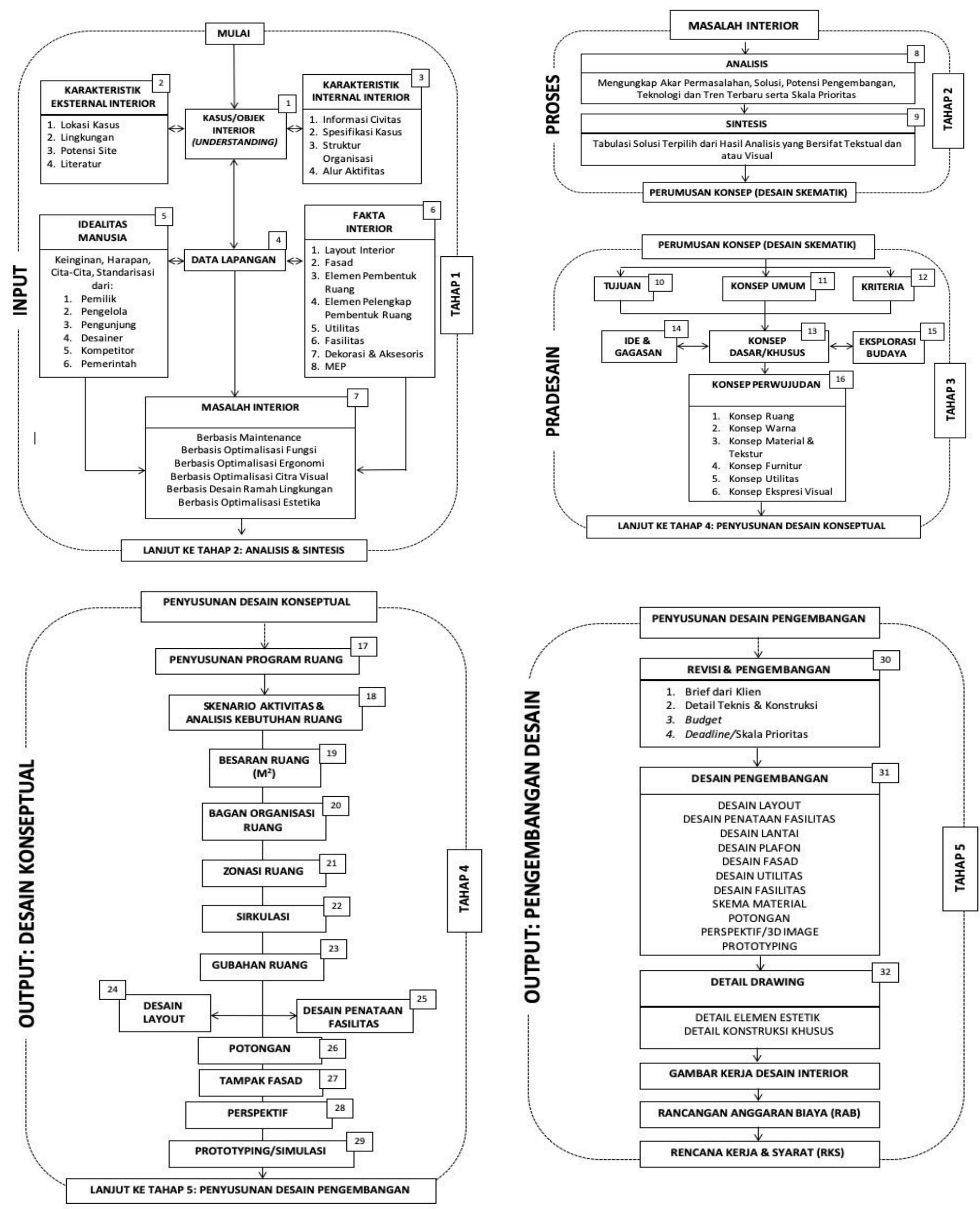

Fig. 2. Skema Metode Desain Interior Rachana Vidhi (Sumber: Penulis 2020) 
Sinergi metode desain interior Rachana Vidhi dengan Revolusi Industri 4.0 diaplikasikan pada data collecting pada tahapan input, modelling pada tahapan pradesain dan desain konseptual. Pada data collecting, mahasiswa diarahkan memanfaatkan big data secara real time, mengenai fakta dan data dari objek kasus eksisting. Pada Tahapan pradesain mahasiswa ditekankan pada insight searching, dengan menggunakan image inspirasi ataupun parameter desain. Mahasiswa juga diarahkan untuk pengembangan ide dan gagasan dengan software mind-mapping dalam menyusun konsep. Pada tahapan desain konseptual, mahasiswa diarahkan mengerjakan gambar kerja dengan manual (hand drawing) baik konvensional ataupun bantuan teknologi (digital drawing), untuk menghasilkan karya yang artistik. Pada tahapan konseptual juga digunakan dalam modelling untuk menghasilkan 3D drawing atupun prototyping. Pada tahapan pengembangan desain, mahasiswa ditekankan penggunaan Computer Aided Design (CAD) 2D dan 3D sesuai dengan standar gambar teknik.

\section{Kesimpulan}

Metode desain interior Rachana Vidhi sebagai kebutuhan konten pembelajaran studio desain pada mata kuliah utama di Jurusan/Program Studi Desain Interior ISI Denpasar, telah diskemakan sebagai panduan bagi mahasiswa. Metode tersebut menggunakan kerangka dasar dari tahapan organisasi profesi HDII sebagai sinergi antara akademisi dengan organisasi profesi. Metode tersebut juga menyeimbangkan pengetahuan dan kemampuan antara akademisi dengan praktisi dengan paradigma research based design. Dalam konteks pengembangan budaya, metode desain interior Rachana Vidhi telah mengisinya pada tahapan Pradesain khusus pada langkah no. 15 Eksplorasi Budaya, sebagai bagian dari penyusunan konsep desain interior. Sinergi dengan revolusi industri 4.0 pada metode desain interior Rachana Vidhi diterapkan pada tahapan Input, Pradesain, Desain Konseptual dan Pengembangan Desain. Aplikasi revolusi industri 4.0 yang digunakan adalah untuk insight searching, data collecting dan juga modelling. Metode desain interior Rachana Vidhi diharapkan menjadi panduan dalam proses pembelajaran pada studio desain, demi meningkatkan kualitas profil lulusan. Namun metode tersebut, tetap membuka ruang untuk evaluasi dan pengembangan, agar lebih praktis digunakan oleh mahasiswa dalam proses pembelajarannya.

\section{References}

Belmawa, Ristekdikti. 2018. Panduan Penyusunan Kurikulum Pendidikan Tinggi Di Era Industri 4.0 (2019). Jakarta: DIRJEN BELMAWA DIKTI, Available at: Google Scholar

Buitrago Restrepo, F, and Iván Duque Márquez. 2013. "The Orange Economy: An Infinite Opportunity.” Washington, DC: Inter-American Development Bank, Available at: Google Scholar

Celaschi, Flaviano. 2017. "Advanced Design-Driven Approaches for an Industry 4.0 Framework: The Human-Centred Dimension of the Digital Industrial Revolution." Strategic Design Research Journal 10 (2), doi: 10.4013/sdrj.2017.102.02.

CIDA. 2010. "Professional Standards." 2010. Available at: accredit.

Grimley, Chris, and Mimi Love. 2018. The Interior Design Reference \& Specification Book Updated \& Revised: Everything Interior Designers Need to Know Every Day. Rockport Publishers, Available at: Google Scholar

Jones, John Chris. 1970. "Method 5.6: Functional Innovation.” Design Methods: Seeds of Human Futures, 331-40, Available at: Google Scholar

- 1992. Design Methods. John Wiley \& Sons, Available at: Google Scholar

Karlen, Mark, and Rob Fleming. 2016. Space Planning Basics. John Wiley \& Sons, Available at: Books Google.

Kilmer, Rosemary, and W Otie Kilmer. 2014. Designing Interiors. John Wiley \& Sons, Available at: Books Google.

Kitchenham, Barbara. 2004. "Procedures for Performing Systematic Reviews." Keele, UK, Keele University 33 (2004): 1-26, Available at: Google Scholar

Kubba, Sam. 2003. Space Planning for Commercial and Residential Interiors. McGraw-Hill, Available at: Google Scholar 
. 2009. LEED Practices, Certification, and Accreditation Handbook. Butterworth-Heinemann, Available at: Books Google.

Kumar, Vijay. 2012. 101 Design Methods: A Structured Approach for Driving Innovation in Your Organization. John Wiley \& Sons, Available at: Books Google.

Liang, Xufang. 2014. "Regional Culture Expressed in Modern Architecture Design.” Cross-Cultural Communication 10 (6): 148-51, Available at: Google Scholar

Lloyd, Peter. 2019. "You Make It and You Try It out: Seeds of Design Discipline Futures.” Design Studies 65: 167-81, doi: 10.1016/j.destud.2019.10.008

Piotrowski, Christine M, and Elizabeth A Rogers. 2010. Designing Commercial Interiors. John Wiley and Sons, Available at: Books Google.

Rohadi. 2017. "Sekilas Tentang Proses Sertifikasi Keahlian (SKA) HDII Di Bali.” In Seminar Kode Etik Dan Sertifikasi Keahlian (SKA) HDII. Denpasar: HDII Pusat.

Rubin, Zachary L. 2012. A Framework for Cross-Cultural Product Design. Georgia: Georgia Institute of Technology, Available at: Google Scholar

Santosa, Adi. 2006. "Pendekatan Konseptual Dalam Proses Perancangan Interior.” Dimensi Interior 3 (2), Available at: Google Scholar

Sugiyono. 2008. Metode Penelitian Pendidikan:(Pendekatan Kuantitatif, Kualitatif Dan R \& D). Alfabeta, Available at: Google Scholar

Yusnaini, Yusnaini, and Slamet Slamet. 2019. "Era Revolusi Industri 4.0: Tantangan Dan Peluang Dalam Upaya Meningkatkan Literasi Pendidikan.” In Prosiding Seminar Nasional Program Pascasarjana Universitas PGRI Palembang. Vol. 12, Available at: Google Scholar 